of BASDAI and ASDAS-CRP, absence of previous infection had a strong relation with low levels of SIgA.

Conclusions: SIgA serum level were the only one serologic maker, which had an inverse correlation with all clinical activity variables of disease, previous infection and some specific antibodies associated with intestinal mucosal infection, suggesting a protective role of this molecular shape of IgA that is characteristic of mucosal immune responses

References:

[1] Mantis NJ. Mucosal Immunol (2011) 4:603-11.

Disclosure of Interest: None declared

DOI: 10.1136/annrheumdis-2017-eular.6159

\section{AB0202 LOW DOSE ACETYLSALICYLIC ACID AS PRIMARY PROPHYLAXIS OF CARDIOVASCULAR EVENTS IN RHEUMATOID ARTHRITIS. A LONGITUDINAL, RETROSPECTIVE STUDY}

D. lacono, S. Fasano, V. D'Abrosca, I. Pantano, R. Chieffo, G. Valentini. Rheumatology Unit, University of Campania "Luigi Vanvitelli", Naples, Italy

Background: Cardiovascular events (CV) i.e. acute myocardial infarction and stroke are recognized as a leading cause of mortality in patients with Rheumatoid Arthritis (RA) [1,2]. Acetylsalicylic acid (ASA) is known to be associated with a significant decrease in the incidence of $\mathrm{CV}$ events in patients at high risk for atherosclerosis like patients with diabetes [3] and has been recently reported to play a primary prophylactic role of CV events in Systemic Lupus Erythematosus by our team [4].

Objectives: To investigate the so far unexplored role of ASA in reducing CV morbidity in RA.

Methods: We analysed patients admitted to our Outpatient clinic from January to December 2015. Out of 199, 155 patients, who had been followed from January 2000 and had not experienced any CV event at the first visit, were enrolled. The incidence of CV morbidity was recorded at December 2016.

Results: The 155 patients had been followed-up for a median of 8 years (range 1-15 years). Out of them, 111 patients had been treated with ASA, that we currently administer to patients undergoing steroid treatment. During the 15 -years of follow up, $5 \mathrm{CV}$ events (2 cerebrovascular, 3 acute myocardial infarction) had occurred (Incidence rate 3.93/1000 person/year). Interestingly, only $1 \mathrm{CV}$ event had occurred in ASA treated patients (Incidence rate 1.12/1000 person/year) with respect to 4 in the non-ASA group (44 patients) (Incidence rate 10.48/1000 person/year) $(p=0.0146)$.

Conclusions: Our study has several limitations including the low number of patients and CV events. Nevertheless, it might suggest a primary prophylactic role of ASA in RA, that awaits to be investigated in large controlled prospective studies. References:

[1] Arthritis Rheum. 2001 Dec;44(12):2737-45. High incidence of cardiovascular events in a rheumatoid arthritis cohort not explained by traditionalcardiac risk factors. del Rincón ID, Williams K, Stern MP, Freeman GL, Escalante A.

[2] BMC Musculoskelet Disord. 2014 Apr 29;15:142. Cardiovascular case fatality in rheumatoid arthritis is decreasing; first prospective analysis of a current low disease activity rheumatoid arthritis cohort and review of the literature. Meek IL, Vonkeman HE, van de Laar MA.

[3] Diabetes Res Clin Pract. 2016 Oct;120:31-9. Aspirin for primary prevention of cardiovascular disease in patients with diabetes: A meta-analysis. Kokoska LA, Wilhelm SM, Garwood CL, Berlie HD.

[4] Rheumatology (Oxford). 2016 Sep;55(9):1623-30. Low-dose aspirin as primary prophylaxis for cardiovascular events in systemic lupus erythematosus: a long-term retrospective cohort study. ludici M, Fasano S, Gabriele Falcone L, Pantano I, La Montagna G, Migliaresi S, Valentini G.

Disclosure of Interest: None declared

DOI: 10.1136/annrheumdis-2017-eular.2858

\section{AB0203 EXPRESSION LEVELS OF SELECTED GENES CAN PREDICT THE INDIVIDUAL RHEUMATOID ARTHRITIS PATIENT RESPONSE TO TUMOR NECROSIS FACTOR ALPHA BLOCKER TREATMENT}

D. Paran ${ }^{1}$, Y. Smith ${ }^{2}$, S. Pundak ${ }^{3}$, U. Arad ${ }^{1}$, D. Levartovsky ${ }^{1}$, I. Kaufman ${ }^{1}$ ${ }_{\text {J. Wollman }}{ }^{1}$, V. Furer ${ }^{1}$, A. Broyde ${ }^{1}$, O. Elalouf ${ }^{1}$, D. Caspi ${ }^{1}$, S. Pel $^{4}$, O. Elkayam ${ }^{1} .{ }^{1}$ Rheumatology, Tel Aviv Medical Center and the Sackler school of Medicine, Tel Aviv University, Tel Aviv; ${ }^{2}$ Genomic Data analysis, Hadassah Medical School Hebrew University, Jerusalem Israel; ${ }^{3}$ Genefron Ltd, Jerusalem; ${ }^{4}$ Rheumatology, Tel Aviv Medical Center, Tel Aviv, Israel

Background: Rheumatoid arthritis (RA) patients have many therapeutic options. However, there are limited tools to predict the individual patient's response to therapy. The Genefron personal diagnostic kit (IFR 300) has been developed based on analysis of large databases to select interferon stimulated gene (ISG) expressions which could predict response to a biologic agent

Objectives: This study aims to evaluate the ability of the Genefron diagnostic kit to predict the individual RA patient response to TNF $\alpha$ blockers.

Methods: Two separate analyses were performed, one retrospective and one prospective analysis. The response of 61 RA patients reported in 2 published data sets was analyzed retrospectively utilizing the Genefron kit. In addition, 18 patients with RA were assessed prospectively, before and 3 months after starting treatment with a TNF $\alpha$ blocker. Clinical assessment included swollen and tender joint counts, patient and physician assessments of disease activity. Patients' blood samples were obtained before administration of the TNF $\alpha$ blocker and were analyzed utilizing the Genefron diagnostic kit which measures expression levels of selected genes by quantitative real time PCR.

Results: Genefron kit analysis of retrospective data correctly predicted the response to a TNF $\alpha$ blocker in 53 of 61 RA patients (accuracy - 86.8\%). In the prospective analysis 6 patients achieved a moderate EULAR response, 6 achieved a good EULAR response and 6 did not respond. According to the EULAR moderate response, the Genefron diagnostic kit predicted the response correctly in 16 of 18 patients (accuracy-89\%, sensitivity - $100 \%$, specificity - $67 \%$ ). According to the EULAR good response, the kit predicted the response correctly in 15 of 18 patients (accuracy - $83.3 \%$, sensitivity - $100 \%$, specificity - $75 \%$ ).

Conclusions: The Genefron diagnostic kit predicted the response to TNF $\alpha$ blockers in a high percentage of RA patients assessed either retrospectively or prospectively in a real life setting. This personal diagnostic kit has the ability to guide selection of a suitable biological drug for the individual RA patient

Disclosure of Interest: None declared

DOI: 10.1136/annrheumdis-2017-eular.2653

\section{AB0204 DISEASE FACTORS ASSOCIATED TO ABNORMAL INTIMA-MEDIA THICKNESS IN MEXICAN MESTIZO RHEUMATOID ARTHRITIS PATIENTS}

D.A. Galarza-Delgado $^{1}$, J.R. Azpiri-Lopez ${ }^{2}$, I.J. Colunga-Pedraza ${ }^{1}$, R.E. Ramos-Cazares ${ }^{1}$, F.J. Torres-Quintanilla ${ }^{2}$, A. Valdovinos-Bañuelos ${ }^{1}$, R.I. Arvizu-Rivera ${ }^{3}$, A. Martinez-Moreno ${ }^{3}$, J.A. Cardenas-de la Garza ${ }^{3}$, R. Vera-Pineda ${ }^{3}$, G. Elizondo-Riojas ${ }^{4}$, J.I. Garcia-Colunga ${ }^{4} .{ }^{1}$ Rheumatology; ${ }^{2}$ Cardiology; ${ }^{3}$ Internal Medicine; ${ }^{4}$ Radiology and Imaging, Hospital Universitario Dr. José Eleuterio Gonzalez, Monterrey, Mexico

Background: Atherosclerotic cardiovascular disease (ASCVD) is the main mortality cause in patients with rheumatoid arthritis (RA) (1). It has been proven that the carotid intima-media thickness (CIMT) measured with carotid duplex ultrasonography (US) is an important ASCVD predictor with a measurement $\geq 0.9 \mathrm{~mm}(2-4)$. Objectives: To characterize the disease factors related with abnormal carotid duplex US findings in Mexican mestizo patients with RA.

Methods: In a cross-sectional setting, we enrolled consecutive RA patients. Patients with overlap syndromes, personal history of ASCVD, dyslipidemia and previous use of any statin were excluded. A board-certified radiologist performed a bilateral carotid duplex US to all patients. Abnormal CIMT was defined as $\geq 0.9$ $\mathrm{mm}$ (hypertrophy $\geq 0.9-1.2 \mathrm{~mm}$ and carotid plaque $\geq 1.2 \mathrm{~mm}$ ). A clinical history and blood tests were performed at the time of the patient's visit. Disease activity was measured with Disease Activity Score using 28 joints-C-reactive protein (DAS28-CRP).

Results: We enrolled 57 patients. Demographic characteristics are shown in table 1. A total of $30(52.2 \%)$ patients had an abnormal CIMT. US findings are shown in table 2. A significant correlation between abnormal CIMT and RA disease duration $(p=0.04)$, as well as between the former and anti-cyclic citrullinated peptide antibodies (ACPA) positivity $(p=0.033)$ was found.

Table 1. Demographic and disease characteristics

\begin{tabular}{lc}
\hline Variable & Results \\
\hline Female gender, $\mathrm{n}(\%)$ & $54(94.7)$ \\
Age (years), mean \pm SD & $56 \pm 9.9$ \\
Disease duration (years), mean \pm SD & $12.4 \pm 8.3$ \\
BMI $\left(\mathrm{kg} / \mathrm{m}^{2}\right)$, mean \pm SD & $28.22 \pm 4.9$ \\
Smoking status, $\mathrm{n}(\%)$ & $5(8.77)$ \\
DAS 28- CRP, mean \pm SD & $3.33 \pm 1.19$ \\
Disease Activity, $\mathrm{n}(\%)$ & \\
$\quad$ Remission & $17(29.8)$ \\
$\quad$ Low & $11(19.3)$ \\
$\quad$ Moderate & $25(43.8)$ \\
$\quad$ Severe & $4(7.1)$ \\
Positive Anti-CCP, $\mathrm{n}(\%)$ & $44(77.19)$ \\
Positive RF, $\mathrm{n}(\%)$ & $51(89.47)$ \\
\hline
\end{tabular}

BMI: Body Mass Index.

Table 2.- Carotid Doppler ultrasound findings.

\begin{tabular}{|c|c|c|c|c|c|}
\hline \multicolumn{2}{|c|}{ Ultrasound findings, $n(\%)$} & \multirow{3}{*}{$\begin{array}{l}\begin{array}{l}\text { Disease } \\
\text { duration }\end{array} \\
\underline{0.022}\end{array}$} & \multirow{3}{*}{ 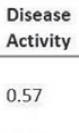 } & \multirow{3}{*}{$\begin{array}{c}\begin{array}{c}\text { Positive } \\
\text { Anti-CCP }\end{array} \\
P \\
\underline{0.034}\end{array}$} & \multirow{3}{*}{$\begin{array}{l}\text { Positive RF } \\
0.14\end{array}$} \\
\hline & & & & & \\
\hline $\begin{array}{l}\text { Abnormal } \\
\text { CIMT }\end{array}$ & $32(56.14)$ & & & & \\
\hline Plaque & $11(19.29)$ & 0.33 & 0.75 & 0.65 & 0.67 \\
\hline Hypertrophy & $21(36.84)$ & 0.52 & 0.59 & 0.54 & 0.38 \\
\hline
\end{tabular}

Conclusions: There is a strong relationship between CIMT and the chronic inflammatory process of RA, as well as ACPA positivity. These results might be influenced by the high mean disease duration of our patients. Prospective studies that evaluate CIMT among disease duration intervals are necessary to support these findings. 